\title{
REFLEXIONES SOCIO-JURÍDICAS SOBRE LA SEPARACIÓN IGLESIA-ESTADO
}

\author{
Luis Cordero Rodríguez
}

\begin{abstract}
Resumen:
Este artículo habla de la separación de la Iglesia y el Estado en los Estados Unidos y de cómo esta separación ha sido beneficiosa para ambas partes. Se habla de cómo en otros lugares se ha intentado hacer lo mismo pero sin éxito, aún si en la Europa Unida actual algunos Estados hayan pretendido lograr esta separación transformándose más bien en Estados laicos y ateos.

Estudiosos en Alemania e Italia han querido copiar para los Estados de tradición católica en Europa, lo que en USA se ha dado en Ilamar "la religión laica" o "religión civil" pretendiendo que el cristianismo tome ese rol, no obstante, poca es la posibilidad de éxito, porque lo que han logrado las diversas Iglesias en A mérica manteniéndose separadas del Estado ha dependido de la historia de los primeros inmigrantes en los Estados Unidos que venían escapando de la tiranía tanto del Estado como de las I glesias. Además, Ia concepción privada de Io religioso que en USA se tiene no es trasladable a Europa, porque históricamente en las naciones cristianas del Occidente Europeo, el Derecho Público se ha introducido en la vida misma de los privados. Hipotéticamente, este cambio sería posible, sólo si en el futuro, Europa regresase a la convicción que se tenía en épocas de la Roma Republicana en la que el Derecho Público del Estado era incompatible con el Derecho Privado de los ciudadanos romanos.
\end{abstract}

Palabras Clave: Religión Civil - Estado Laico - Estado e Iglesia.

\begin{abstract}
A bstract:
As a professor he used to teach the excellency of the "establishment clause" in the American Constitution about the relationship between the Churches and the A merican State. Precisely in the present article he presents this excellency, and studied the impossibility for the European and West Christian Countries, to copy this American way, because the History of the different Christian Countries are, by no doubt, very different, and cannot be compared with the History of USA and its different religion Confessions. Also the conception of Privacy is very different in those countries. In fact, nearly all of the different European Countries use the Public Right of the State in all events of Private life
\end{abstract}

* Rector de Facultad de Teología Pontificia y Civil de Lima en el período 2003-2005. Decano de la Facultad de Derecho de la Universidad de Lima en el período 1990-1993. A bogado de la Rota Romana. 
(School, Religion, Taxes, Welfare, etc), which is exactly the opposite way done by USA where Privacy is sacred; and Religion is in the field of privacy, therefore it is incompatible with Public Life, and any Church cannot be on welfare (or on US social Security).

Key words: Civil Religion - Secular state - Church and State.

\section{Sumario:}

1. ¿El Estado debe ser Laico? 2. La figura en USA y en Europa. 3.¿Será exportable este concepto de "religión civil"? 4. ¿Se podría tomar al "Cristianismo" como si fuera esa religión civil para Europa? 5. Estado Laico en Europa 6. El caso peruano. 7. El Pluralismo religioso según el Papa bueno. 8. La visión de Juan XXIII y el Pluralismo político actual.. 9. Conclusión.

\section{1. ¿EL ESTADO DEBE SER LAICO?}

H ace muchos años cuando estudiábamos en San Marcos, allá por los años 50, aprendimos en Antropología que algún día todo en el mundo sería globalizado; de lo contrario el ser humano se hundiría en una masificación total. N osotros, los estudiantes de aquella época, sin frisar aún los 21 años creíamos que eso era una utopía y una exageración, y que por lo menos nosotros nunca lo veríamos, así como nunca veríamos un Estado laico separado de la I glesia, o una China capital ista, o una Rusia no comunista, o una Alemania social demócrata. Hoy a los 50 años de ese estudio, tenemos que reconocer que nuestros cated ráticos de entonces sabían lo que decían, porque todo lo anterior se ha cumplido y hasta el Estado laico lucha para llegar a ser una real idad global izada, por lo menos en el Occidente del siglo $\mathrm{XXI}$.

\section{LA FIGURA EN USA YEN EUROPA}

Antes de hacer cual quier otra consideración socio-jurídica, sobre el Estado laico, permítasemerefl exionar en primer lugar sobre lo quevoy a llamar una "religión civil", que es la que existe como fenómeno en los Estados Unidos; y en segundo lugar sobre lo que yo pretendo llamar un "Estado laico" que parece ser una esperanza que pretende consumarse como fenómeno actual en la Europa Unida.

Sé que para muchos estos tipos de "ideales" y hasta de vocablos pueden sonar a una simplificación grotesca de la realidad porque tanto la primera 
como la segunda figura pudieran co-existir mezclándose y confundiéndose entre si; pero vál game esta simplicidad para introducirme en la materia.

Decir "religión civil" o "religión laica" suena disparatado y hasta discutible porque el solo concepto no podría dejar de tener en sí al guna connotación o alguna dosis de creencias o símbolos casi religiosos, a todas luces perennes; (como la bandera y el himno nacional, por ejemplo). Cuando digo "religión civil" en USA quiero decir que existen en los Estados Unidos de A mérica ciertos elementos civiles en su sociedad que tienen aparentemente rasgos comunes de orientación religiosa, compartidos por la gran mayoría de los norteamericanos. En efecto, tales rasgos son los que han influido y determinado el desarrollo de las Instituciones en ese país, y aún más, parece que siguen contribuyendo hasta ahora en darle una dimensión civil- religiosa a todo el complejo de la vida norteamericana incluyendo su vida política.

El término "religión civil" no es mío, es un término acuñado hace ya 30 años y que yo lo he tomado prestado de Davis, de Ferrari y de Roberto Bellah ${ }^{1}$. Según este último los elementos que forman una "religión civil" en una sociedad concreta, son: la aceptación por todos de la existencia de un Dios trascendente, la creencia en que la vida es eterna, la fe en que las buenas acciones serán recompensadas y que las malas tendrán su castigo, y además la exclusión de cual quier intoler ancia religiosa.

La Constitución Americana en su "primera enmienda" presenta una cláusula cerrada que ellos llaman "establishment clause ${ }^{2 "}$, en la que se establece de una vez para siempre en forma inmodificable que el Estado A mericano no podrá sostener económicamenteni defender oficialmente a al guna confesión religiosa o Iglesia en particular; aunque los privados sí puedan hacer manifestaciones específicas externas de una religión popular expresada civilmente, sin participación del Estado para que éste no se identifique oficial mente con ella o con al guna otra religión o confesión histórica. Para los norteamericanos esto no es ningún obstáculo, por ejemplo, para al udir a Dios en la "Declaración de Independencia" o para admitir alguna oración genérica que no se refiera a confesión religiosa al guna, al abrir las sesiones del Congreso. Aún más, esto no impide que el Estado mande imprimir en los billetes de un dólar la confianza queel pueblo tieneen Dios, (in God we trust) o proclame en los oficios públicos que "América es una Nación que está bajo la protección de Dios" ("a Nation Under God”). 
Tales referencias permitidas por la Constitución de los Estados Unidos reconocen que por encima del Estado existeuna Ley Natural cuya fuentees un Ser Supremo que es antecedente y superior a la voluntad del hombre americano: Ley Natural que contiene principios y valores que son como las columnas sobre las que el Estado debe construir una especie de religión civil que no está sujeta a votación popular al guna. En efecto, el Presidente norteamericano jura anteel Pueblo y ante Dios en la ceremonia de la toma de posesión de su cargo, pero no ante algún Pastor, Rabino u Obispo, porque considera que las personas que votaron por él son en su mayoría el medio operativo de la voluntad política divina, en toda su dimensión, aunque esa votación no posea en sí misma un significado ulterior porque según la misma Constitución eso corresponde más bien al patrimonio del Bien Común que es un Derecho y un Orden Constitucional reclamado por todos Ios ciudadanos americanos, porque proviene de la Ley Natural y al que está ligado el mismo Estado.

La voluntad popular entonces para USA no es en sí misma el criterio último en el que se basan los jueces para determinar si al guna disposición o al guna conducta pública es justa o es errónea. Existe según la Constitución de los Estados dela Unión, un Criterio Superior al mismo pueblo en baseal cual se puedesaber si el pueblo y sus gobernantes obran en forma justa o equivocada.

En la historia de los Estados Unidos encontramos el camino que los norteamericanos han seguido para encontrar los posibles "déficits" o "superávits" sociales de su propio "ethos"que le han permitido construir una sociedad civil y religiosa con criterios compartidos equilibradamente por toda la comunidad nacional americana porque se han ido formando poco a poco durantevarios siglos, en las personas que han llegado a A mérica de todos los rincones del mundo sin importar sus creencias religiosas. De esta convivencia tan dispar se ha derivado el núcleo de los valores compartidos por todos los actuales ciudadanos independientemente de la religión o de cualquier otra convicción personal a la que cada uno pudiera haberse sentido ligado en su lugar de origen. De esta historia ha provenido el mito actual que tienen los norteamericanos de formar una Nación con una "misión histórica" en el mundo, confiada a ellos por Dios para exportar y diseminar su democracia o "la democracia" a todas partes, y hasta para creerse "la policía moral" del Universo. Misión, convicción y mito de los que actual mente participa en forma particular cada ciudadano de esa gran Nación. 
Al decir "religión civil" me estoy divirtiendo porque observo la existencia de una realidad en la que el Estado está verdaderamente separado de la Religión Organizada, (Ilámese o no Iglesia), pero que busca un subrogado que llene este vacío. Es por esto que a causa de esta separación se ha ido creando la convicción nacional de que la sociedad civil americana y no la sociedad religiosa, es la encargada de tomarse a sí misma, o a su estilo de vida y a su orden social, como la solución moral natural para todos los problemas sociojurídicos y religiosos del mundo entero. (Este mito sería también parte de lo que llamamos "religión civil" en USA).

La misma Iglesia Católica de los Estados Unidos para sentirse norteamericana, tiene una organización política eclesial interna que señala en forma definitiva y práctica que ella no quiere nada con el Estado de quien se siente separada, rechazando con énfasis que el Estado pueda asumir cual quier forma de confesionalidad, ni siquiera la católica, sin que por ello se si enta obligada a renunciar por completo al uso de los símbolos y de los valores contenidos en el cristianismo ${ }^{3}$. Según los cristianos de A mérica, la separación de la Iglesia y del Estado no se ha introducido en esa Nación para "laicizar" el Estado, que ya de suyo es laico, aunque no pagano, sino para defender el derecho que el pueblo tiene al "pluralismo" y a la libertad religiosa, los cuales se perderían si existiera una fusión entre la Iglesia (o "las Iglesias"), y el Estado.

En muchas sentencias Judiciales Supremas de los Estados U nidos, se señala que el "establishment clause" se debe interpretar en el sentido de que esa cláusula impide a la A dmi nistración pública y política americana, cual quier favoritismo no sólo a una confesión o religión particular, sino también al "ateismo" o al "agnosticismo", estén éstos organizados o no.

Este criterio civil-religioso ha producido en los Estados Unidos la conciencia nacional de que sólo el Estado posee el rol necesario para producir la "unidad" global de toda su población, sin importar cual haya sido el origen étnico, o religioso de al guno de los 50 estados que la componen.

Es verdad que esta concepción generalizada en el pueblo a veces ha ocasionado al guna tensión en ciertas minorías o grupos religiosos en USA, sobre todo en aquellos grupos de origen no cristiano ni judío; o en aquellas minorías y grupos que se consideran agnósticos o ateos. Esta aconfesionalidad (repito no pagana)ha producido por otra parte, un 
acercamiento étnico detodos los ciudadanos, quehan aceptado como válido el lenguaje ético y hasta teológico pero no confesional usado por algunos presidentes como Lincoln, Reagan, Carter y hasta por el mismo Bush que algunas veces se ha proclamado como el escogido por Dios para salvar la humanidad.

\section{3. ¿SERÁ EXPORTABLE ESTE CONCEPTO DE “RELIGIÓN CIVIL”?}

Ahora bien, nos corresponde reflexionar sobre la posible suerte de este criterio americano si es que quisiéramos utilizarlo fuera de USA en el resto del mundo, o por lo menos en las comunidades occidentales latinoamericanas o europeas afines a las de USA por su democracia. No será difícil adivinar la suerte que tendría este criterio de "religión civil"en esos Estados no americanos, porque los factores quese dieron en la formación de la Sociedad de los Estados Unidos, no son los mismos quesehan dado en el resto del mundo occidental. Para analizar bien y sin pasiones este fenómeno, reflexionemos cómo fueque Los Estados Unidos de América Ilegaron a esto. En real idad es una figura jurídica que ti ene en cuenta la trayectoria histórica norteamericana en la formación con éxito, de un Estado aconfesional no pagano causada, como digo, por la historia a través de dos factores que han producido este efecto socio-religioso. P or un lado la causa remota estuvo en la existencia desde los inicios de un pluralismo confesional que pudo convivir como resultado de la inmigración europea en USA empezada a fines del siglo 17. Este pl uralismo es el que precisamenteimpidió la formación sociopolítica de una única religión oficial en las mayorías americanas. Por otro lado, Ia historia nos refleja que desdeel principio los primeros inmigrantes a A mérica trajeron consigo una desconfianza frente a un Estado absoluto y frente a una Iglesia intransigente. En efecto estos primeros inmigrantes que provinieron de Europa emigraron para A mérica precisamente para escaparse del yugo religioso o de la rigidez estatal. Todo esto ha hecho que en USA el desarrollo gradual de una Administración pública se acostumbrase a prescindir de las confesiones y credos religiosos. La Sociedad civil de USA fue odiando poco a poco todo lo religioso que pudiera aparecer como de D erecho público oficial porque una fusión oficial de ambos derechos civil y religioso, hubiera más bien dividido a los Estados de la Unión, y por eso la sociedad americana prefirió organizarseen todas las áreas social es en forma privada sin intervención del Derecho Público. El mismo Common Law utilizó para esto el carácter privatístico del viejo Derecho Romano considerado desde el siglo XI como Derecho privado común para todo el Occidente. 
Con sólo esto, ya se ve cuán difícil sería exportar este sistema a la Europa actual que aún tiene lazos con el sentido medieval de la religión, o con la forma pública del Derecho postreformista y decimonónico queha permitido la persistencia actual en la mente de muchos europeos de la ética leninista de las masas, del talante anticlerical de algunos pueblos, y del Derecho de clases, unidos a un anticlericalismo existente sobre todo en Estados que otrora fueron católicos a ultranza como Francia, Italia y España.

Si analizamos además la historia de la formación social europea después de la Unidad italiana y alemana encontraremos aún más difícil la exportación a Europa de estemodelo de sociedad política americana ${ }^{4}$. Es verdad que en Europa hubo también un pluralismo confesional pero en cada Estado prevalecieron varias organizaciones religiosas particularmente cristianas y católicas que han contribuido poderosamente a construir paradigmas nacional es con ritos eideales enraizados en ciertos pueblos, hasta desarrollar en base a ellos la identidad de cada Nación. Una "religión civil" de estilo norteamericano caracterizada por un Dios "impersonal" en el que todos, no importa si musulmanes, hindúes, cristianos, judíos o ciudadanos con filosofía Kantiana se pudieran reconocer, no podría ser posible creo yo, en la Europa actual, porque esta figura ya traería adversarios con sólo nacer, porque estas mismas confesiones religiosas serían las primeras que reaccionarían contra ella porque no estarían dispuestas a que su función histórica pudiera olvidarse o terminar en un "ghetto", puesto que sienten que ellas son aún ahora la fuente histórica de la supervivencia civil de sus pueblos ${ }^{5}$. Esta hostilidad es común entre las grandes religiones existentes en Europa porque están convencidas que aquello de la religión civil a la americana sería como un Caballo de Troya que pretendería infiltrarse en Europa para ampliar paradójicamente la influencia de las diversas confesiones religiosas en la esfera pública, escondiendo bajo la etiqueta de "religión civil" la reivindicación del cristianismo en el norte de Europa y del catolicismo en la Europa Central y M eridional hasta el punto de seguir pretendiendo dar continuamente las pautas directrices de una ética pública sin decir que sea confesional.

Por otra parte en los países de Europa el llamado "aparato estatal" tiene un rol bien relevante (en cantidad y calidad) en cada Estado y Nación, Ilámese I talia, Francia, España, Alemania, H olanda, o Reino Unido, y es el Estado el que se encarga (al revés de los Estados Unidos) de tareas bien concretas en la educación, en la salud, en la asistencia y previsión social y hasta en la 
misma economía familiar (lo que en los Estados Unidos está totalmente en manos de los privados).

En estecontexto en Europa existe una ligazón estrecha en cada región entre la I glesia y el Estado (hasta en la tributación) y son ya muchos los siglos en que se han conservado las diversas competencias entre los Estados y los organismos eclesiales o religiosos oficiales.

Esto pues imposibilitaría a mi juicio una vuelta de timón en los Estados europeos que sería la única forma drástica para llegar al verdadero separatismo institucional entrelas distintas I glesias y los Estados europeos, por lo que creo que sería poco menos queinviableel establecimiento de una "religión civil" al estilo americano en la Europea actual.

Mi insistencia puedeser irritante, pero es quecreo que sería verdaderamente una utopía pretender en Europa que el ementos religiosos que ya tienen un perfil propio en la vida pública milenaria europea se articulasen diversamente para obtener un equilibrio sociorel igioso que hoy no existe, 0 un equilibrio entre la Iglesia y el Estado al estilo de los Estados Unidos cuya Constitución cuida bien de que la Pública Administración A mericana no favorezcajamás a una religión por encima de otra, einclusive por encima de la "irreligión" (para usar el término Constitucional americano que explicita que no debe existir "religion over irreligion"). En USA se ha podido controlar inclusive la enseñanza de la religión en las escuelas del Estado, sin perder el sentido de la libertad.

En Estados Unidos esta figura no ha tenido el impacto que pudiera tener en Europa porque la mentalidad y casi sacralidad de lo privado en USA es decididamente más poderosa y fuertequela mentalidad de hacerlo todo por el sector público. Contrariamente a esto, en Europa en general la escuela, la salud pública, la familia y muchas otras figuras o temas centrales de la vida social están aún ahora en manos del Sector público.

Una cosa es prohi bir la enseñanza de una religión exclusiva en las escuelas públicas en un Estado como el norteamericano en que la mayor parte dela vida social está en manos de los privados, y otra cosa sería prohibirla en aquellos Estados en que la escuela y la vida social en general están mayormente influenciadas desde siglos, por la mano pública del Estado, o dela Iglesia. ${ }^{6}$. 
Importar a Europa la concepción americana de una "religión civil", creo yo que implicaría para muchos países, proceder drásticamente a una laicización de todas Ias Instituciones Públicas que ni Ias I glesias ni la misma sociedad civil del Reino Unido, de Italia, España o Francia aceptarían, (ni los Estados parece que estuvieran dispuestos a introducir).

\section{4. ¿SE PODRÍA TOMAR AL “CRISTIANISMO” COMO SI FUERA ESA RELIGIÓN CIVIL PARA EUROPA?}

Desde mi punto de vista como ya el lector se habrá dado cuenta, trasplantar a Europa la experiencia de la religión civil norteamericana, es al go rayano en lo imposible. Sin embargo hay estudiosos y hombres políticos en Alemania, el talia que han avanzado el criterio de que sí puede ser posible establecer un camino para que sea el cristianismo el que funcione como "religión civil" en Europa. (Así lo señalan Ferrari ya citado, y Cole, Durham y Sewell en un trabajo conjunto sobreel Derecho y la Religión en una Europa post-comunista; publicado en la revista "Il Mulino", Bologna 2004 pp. 501523).

Estos autores realmente sólo usan el término de religión civil americana, en forma vacía, sin su contenido. Al referirse al "cristianismo" como religión civil de los Estados europeos ellos mismos reconocen que en Europa se requerirían de estrategias total mente distintas de las usadas por los Estados Unidos para lograr una religión civil o laica. Pero veamos lo que proponen a pieforzado.

Parten ellos del convencimiento que tienen de que el cristianismo ha sido y seguirá siendo el único punto de apoyo indiscutible en la forja del Occidente europeo. Dicen ell os que para dar auténticas garantías de éxito en crear una Europa unida con una figura laica y religiosa a la vez sin perder la actual coyuntura liberal y democrática europea, se requeriría afianzar mejor la unidad de sus fundamentos morales en la convivencia, y tener en lo posi ble también una unidad en la visión común del mundo. Por eso ellos creen que en la tarea unificadora no se puede prescindir del cristianismo quees el patrimonio común indiscutible en Europa, y el único según ellos que tiene la capacidad de "alimentar", en una óptica no confesional y respetuosa dela libertad religiosa, no sólo la distinción entre la Iglesia y el Estado sino también la conservación de algunos valores 
fundamentales y éticos. Sólo así se podrá lograr una única identidad para todas las naciones europeas.

En realidad yo no he encontrado en su propuesta un claro derrotero de lo que hay que hacer o conseguir, para lograr lo que los Estados Unidos han logrado. Sólo veo reflexiones atinadas pero no concretas para llegar a la meta.

Estas reflexiones que a continuación acoto, me parecen válidas aunque no veo ninguna propuesta precisa para lograr concretar la forma de hacerlo.

1. Parten de la observación de que la secularización de la vida social europea al tratar de copar todos los campos de la sociedad ha olvidado reconocer de hecho queen la formación de la unidad europea la religión cristiana ha tenido un valor civilizador indiscutible.

2. Señalan estos autores que cada vez más los ciudadanos europeos, a pesar deno ser ya practicantes desu religión, seadhieren a los símbolos cristianos en la expresión de su cultura (arte, arquitectura, literatura, filosofía, etc.).

3. Según ellos el pueblo europeo, de verdad quiere llegar a tener una "religión civil"a la americana sin el yugo de lo religioso ni del aparato estatal. Pretenden probar esto, constatando que casi todos los pueblos para atraer al turismo suelen referirse a sus bases culturales de origen cristiano, que por tradición han logrado en todos los siglos grandes transformaciones sociales, religiosas, económicas y culturales.

4. Creen ellos que invitar a los europeos a quetengan al cristianismo como base para llegar a crear una religión civil, es al go que va a ser aceptado por las mayorías porque lo estiman como una exigencia natural compartida por casi todos.

Esto responde, según estos autores al albur que se les presenta actual mente a los europeos para construir un mundo más acorde con el siglo XXI. El cristianismo, dicen, ha sido una de las columnas central es en las que se ha construido históricamente la identidad europea, y por eso apelando a la historia del arte, y de la literatura, concluyen que aún hoy el cristianismo puede contribuir a orientar más profundamente a los jóvenes europeos en su quehacer histórico. Su argumentación sebasa en las ideas propaladas por el Plan del Comisariado General para el proceso de la construcción de Europa Unida con sede en Paris (" $\mathrm{La}$ documentation francaise"; París 2002 p.15). 
5. Este Plan del Comisariado en resumen dice: "el estilo de la vida política europea, el contenido de los debates públicos sobre los problemas sociales y éticos, la definición de la responsabilidad del Estado y del individuo, el concepto sobre ciudadanía, la comprensión de la naturaleza y la ecología, las reglas concretas de la civilización, el uso del dinero y la sociedad de consumo en Europa están impregnados de criterios cristianos".

6. Dicen ellos, que este proyecto Ilenaría el vacío de algunos valores occidentales que se han visto debilitados en el proceso de la unificación europea, la que debería pasar de una realidad de unificación económica a una entidad política y cultural unificada.

7. No importa, dicen ellos, que las iglesias permanezcan vacías si el ambiente cristiano es capaz de permear el patrimonio cultural de Europa.

8. Señalan al final, que inclusivelos Concordatos firmados por los diversos Estados y la I glesia Católica después del Código Canónico de 1983tienen otra configuración (Los más recientes han sido firmados con Polonia, Lituania, Croacia, República Checa, Italia, Malta, y España) porque en ellos particularmente ya no se hace referencia a fórmulas confesionales, sino tienen más bien connotados seculares en que los Estados civilizan algunas normas canónicas, y la I glesia canoniza al gunas normas civiles. En estos tratados, la religión ya no es una premisa para la relación I glesia-Estado, y la presencia católica en esos pueblos se transforma más bien en una orientación cultural y ética para que los legisladores se inspiren cristianamente en el desarrollo de sus actividades, particularmente en lo referente al derecho de familia, y a las normas sobre la escuela. (En el Perú se firmó el Convenio I glesia-Estado, con estos criterios, en julio de 1980, criterios que primaron en la codificación canónica de 1983).

Aún así, si selograsen estas premisas, creo yo que se habrán de presentar posteriormente muchas dificultades en el lenguaje y en el pensamiento delas naciones europeas para aplicarlas, porque ni los católicos piensan como los luteranos, ni éstos piensan como los anglicanos, ni los griegos ortodoxos piensan como los ortodoxos rusos o turcos, aunque todos se sientan auténticos cristianos.

Creo yo que la Europa actual no tiene los medios aptos para lograr un pluralismo religioso con valores cristianos y con una única ética. Creo aún más que el estilo privado americano de su libertad religiosa, difícilmente podrá llegar a tener un mismo lenguaje en la Europa actual sin vaciar su contenido cristiano. 


\section{ESTADO LAICO EN EUROPA}

El presidente francés Jacques Chirac pronunció en el 2003 un discurso con connotados políticos, cuando surgió la controversia sobre el uso del velo islámico en los col egios (velo usado por motivos religiosos). Fueron cél ebres las frases lapidarias que él usó, dirigiéndose a todos los europeos:

"Lo laico se encuentra en el corazón de nuestra identidad republicana y exige un cierto grado de desapego del ciudadano europeo de todo lo que le pertenece por derecho público para derivarlo exclusivamente al orden de lo privado".

Con esto señalaba a nombre de Europa que "el espacio religioso particular de cada ciudadano debería separarse por completo del espacio público".

En esta perspectiva, el "Estado laico" en Francia, debería asumir las características de una casa común para tod os los ciudadanos, a donde y de donde pudieran entrar o salir todos a su antojo precisamente porque esta casa no debería tener al gún distintivo particular confesional, cultural o étnico. Esto, dicen los franceses "permet á la France de ne pas etre una juxtaposition de communautés".

Puede ser que si se empezara a creer en, o a crear un « Estado laico » podría llegarse al gún día a concebir (empezando por Francia) una neutralidad del Estado y de la sociedad civil europea frente a cual quier convicción religiosa tradicional, para poder llegar a la neutralidad y al pluralismo de las instituciones públicas. Esta neutralidad y pluralismo serían el presupuesto que consentiría al ciudadano de a pie, conservar su fe y profesar al mismo tiempo veneración por sus raíces étnicas.

- ¿Se podrá llegar a esto algún día? - No creo que sea una cosa tan sencilla. Podría eso sí marcar el primer paso para llegar al pluralismo social en Europa y con éste al pluralismo religioso, porque ofrecería un sustento equitativo a la libertad religiosa de todas las confesiones.

- No meatrevo a pronosticar nada ni para el Occidenteen general, (ni menos para el Perú en particular). Tal vez dentro de 50 años al guien constatará que la "religión civil" o "laica" sea un hecho en Occidente.

No quiero cerrar mis reflexiones sin hacer notar antes lo que es ya una realidad en Europa y en A mérica Latina sobre Estados que se manifiestan 
frentea la I glesia como laicos más no ateos. Me baso en el estudio hecho por A.W. Ziegler en dos tratados, hoy día consi derados clásicos en esta materia: "Das Verhâltnis von Kirche und Staat in Europa" (Munich 1972) y "Das Verhâltnis von Kirche und Staat in A merika (M unich 1974).

Este autor clasifica la relación occidental entre Iglesia y Estado en cinco sistemas: sistema laico, sistema aconfesi onal, si stema asépticamente laico (o ateo), sistema concordatario y sistema de separación coordinada. Veamos:

1. Llama "sistema laico" al que ha sido adoptado por aquellos Estados que no quieren una relación oficial con la I glesia pero que afirman deal guna manera queen su Constitución segarantiza la libertad religiosa detodos los ciudadanos y de las comunidades religiosas formadas libremente por ellos (Es el caso dela religión civil en USA).

En esta figura el Estado se proclama total mente separado de la Iglesia con la prohibición constitucional de reconocer oficialmente que exista una religión de Estado, pero en donde se respetan los val ores religiosos de la sociedad. La Iglesia en esta figura se deberá adecuar al derecho civil común si es que quiere constituir asociaciones religiosas, pero todo lo que haga la Iglesia con el pueblo, debe considerarse de Derecho Privado. Esto es lo que ya hemos presentado como la figura de "religión civil" en los Estados Unidos de América, y que ha servido de base para la redacción de la declaración de los derechos universales y de los derechos a la libertad religiosa en la ONU.

2. El autor presenta también Ia figura de un Estado con "sistema aconfesional" en donde hay separación total del Estado con cualquier credo o confesión, y en donde no se profesa ni siquiera la creencia en algún Dios. Estos son:

En Europa: Andorra, Bélgica y Francia

En A mérica: Canadá, Chiley Uruguay

En A sia: Bhutan, China Nacionalista, Corea del Sur, India, Israel, Japón y Turquía

En África: Guinea, Tanzania, Tanganika y Zanzíbar.

3. El autor señala además la existencia de naciones que se profesan asépticamente laicas (o ateas) y señala como ejemplo a Francia y a las que se declaran haberse separado de aquella I glesia a la que un tiempo el Estado la tenía como I glesia protegida.

4. Precisamente por haberse desligado de la I glesia oficial católica, al gunos 
Estados han firmado concordatos o convenios con la Santa Sede. Señala como desistema concor datario:

En A mérica: Ecuador, Venezuela, Bolivia, Perú y El Salvador.

En Europa: Alemania, (y sus Estados internos como Baden, Baviera y Renania) Austria, España, Francia, Italia, Portugal y Suiza.

En A sia: Filipinas.

5. El autor presenta otras naciones que han preferido elaborar una separación coordinada, con varias iglesias cristianas como Bélgica, Holanda y Luxemburgo, en Europa; y como Brasil, Canadá y Chile en A mérica.

6. El caso de M éxico es único porqueen su Constitución se declara Estado ateo y contrario a cualquier tipo de religión, y enemigo de la Iglesia católica en particular. Sin embargo mantiene una discreción ante la persona del Sumo Pontífice, y acepta la existencia en su Nación de un Delegado A postólico como diplomático.

\section{EL CASO PERUANO}

El autor no lo estudia en forma especial y yo prefiero dejar a otros que hagan un estudio especializado sobre el particular, porque el Perú, es una Nación abiertamente religiosa con un Estado cuya relación histórica con Ia I glesia no ha sido uniforme porquetuvo épocas en que se identificó total mente con la Iglesia católica y otras épocas en que el Estado le confiscó sus bienes. Tuvo épocas en que los Obispos eran nombrados por el Congreso y otras en que los Obispos eran considerados como vasal los del Estado ll egando hasta la frialdad y el desprecio a las leyes de la Iglesia cuando se firmó la Constitución de 1933 obligando antes al A rzobispo de Lima M ons. Lisson a un autodestierro en Valencia España.

Es verdad que el pueblo peruano es muy religioso pero esto no significa necesariamente que sea cristiano, porque la religiosidad es un elemento espiritual que suele ser más bien emotivo y sentimental, mientras que el cristianismo es una religión revelada más bien cerebral y de compromiso, que no siempre es bien comprendida. Todo esto exigiría un estudio muy especializado que no es el caso para este ensayo.

No puedo concluir estas reflexiones en forma abrupta. Deseo antes de finalizar presentar las enseñanzas del Papa Juan 23 sobre el Estado y la Iglesia para un mundo plural y a la vez globalizado que ya se veía venir 
desde los años 60 del siglo XX. Su enseñanza la plasmó en la Encíclica "Pacem in Terris".

\section{EL PLURALISMO RELIGIOSO SEGÚN EL PAPA BUEN O:}

El espíritu de los tiempos actual es decía el Papa en 1963, está dominado por la lógica del encuentro y del desencuentro delas civilizaciones. No se puede exigir hoy quetodos los pueblos piensen igual y que estén adheridos entre sí ni intelectualmente ni emotivamente. Hay evidente dificultad de entendimiento por ejemplo entre cristianos y musulmanes, entre judíos y árabes, y en general entre los pueblos de Oriente y los de Occidente. Sin embargo con respecto a los pueblos de Occidente el Papa bueno encontró suficientecapacidad y competencia en el los para poder hacer que convivan lo laico con lo religioso sin excluirse entre sí. El Papa constató que muchas leyes en el Occidente se seguían dando con una inspiración cristiana, posiblemente "secularizada" pero llena del sentido moral cristiano existente dentro de la vida privada de cada uno.

Desde 1963, año de la encíclica, hasta el 2007 actual, el mundo cristiano de Occidente ha evolucionado mucho. A quel antiguo binomio que luchaba entre la sacralización de la vida privada y la laicización de la vida pública, hoy día es más bien el camino para llegar a un sano pluralismo "post moderno". El pluralismo actual podría ser el vínculo auténtico que poco a poco logrelo que el Occidente ha buscado siempre aunque a veces sin éxito, para armonizar la privacidad de la fe con las convicciones políticas actuales, y para lograr el respeto de lo religioso en el escenario de la vida pública. La gente en el 2007 quiere usar medios no necesariamente liberales para convivir, armonizando la paz de la vida privada con la de la vida política pública. Estoy pensando por ejemplo en el respeto del uso del velo islámico en Europa, o en la adecuación de las leyes europeas para quel os musulmanes inmigrantes tengan sus horas de oración durante el trabajo, o para la aceptación de la poligamia en aquel los Ilamados extracomunitarios árabes que viven por ejemplo en Boloña, Italia; y para otras situaciones contradictorias que quieren convivir con pueblos de costumbres ancestralmente cristianas de la Europa actual, sin ser discriminados. Es cierto que los europeos sienten que el piso se les derrumba al sólo pensar que estas costumbres no cristianas se vuelvan consentidas por las Instituciones europeas; pero al mismo tiempo sienten que la grandeza de Europa está precisamente en su diversidad, y que por lo tanto los europeos 
debieran ser capaces de ser a la vez cristianos y laicos pero no paganos, con lo que no importaría si en un pueblo los crucifijos estén colgados en las paredes y en otros sean quitados de los col egios, o si en unos Estados el uso del velo islámico sea tolerado, y en otros esté prohibido.

Sin embargo, actual mente empieza a preocupar al europeo la existencia de un pluralismo religioso y cultural compatible con sus Instituciones Públicas, porque sienten que un pluralismo de ese tipo podría llegar a obligarles a renunciar al derecho de impedir que un sistema de val ores no europeos se apodere de las Instituciones estatales y las transforme poco a poco hasta perder la identidad de lo europeo.

Si el Estado europeo por rechazar el plural ismo se declarara "asépticamente laico", correría el riesgo deno interesarseya en buscar la verdad, y habría de aceptar su propia incompetencia para defender o rechazar al guna lógica de tono espiritual, por lo que habrían de resignarse a dejar lo trascendental en manos de las agencias especializadas (Ilámense o no Iglesias).

Esto nos obliga a releer el pensamiento del Papa Roncalli y entenderlo mejor, aplicándolo al hoy que vivimos, utilizando lo que él mismo llamó el aggiornamento.

\section{LA VISIÓN DE JUAN XXIII Y EL PLURALISMO POLÍTICO ACTUAL}

En su encíclica "Pacem in Terris" números 143 y 144, el brillante Papa Roncalli a sabiendas de la desconfianza de los papas del siglo 19 que no querían quese redactasen al gunas declaraciones delos derechos del hombre, porque según ellos estas declaraciones revivirían las crisis de la revolución francesa y podrían poner al hombre orgullosamente por encima de Dios, a pesar de esto digo, el Papa bueno insiste en su encíclica en afirmar que "uno de los actos más importantes llevados a cabo por la ONU en el Siglo XX ha sido la Declaración de los derechos del hombreaprobada el 10 dediciembre de 1948 en la Asamblea general de las Naciones Unidas". El Papa enfatiza que desde el preámbulo esta Declaración "proclama como objetivo común la promoción por todos los pueblos y naciones del reconocimiento y del verdadero respeto de todos los derechos y libertades del hombre" (143)... "Nosotros consideramos (dice el Papa) esta Declaración, como el paso más seguro para establecer una organización jurídico-política dela comunidad 
mundial". Dice el Papa que esta Declaración "afirma para cada individuo su derecho a buscar libremente la verdad, a seguir las normas morales, a practicar los deberes de justicia, a exigir las condiciones de vida de acuerdo a la dignidad humana así como a conseguir otros derechos ligados a ésta" (144).

Esta idea del Papa bueno no se debió sólo a su capacidad para descubrir y animar todo lo que era bueno, sino que el Papa puso esta Declaración como la base común y el terreno hábil para el entendimiento pluralista del hombre que debe convivir con horizontes diferentes, con doctrinas propias que a veces parecieran incompatibles entre sí, pero que hay que desarrollar para encontrarse y establecer una comunidad jurídica y política mundial, que una y no distancie a los pueblos.

En la quinta parte de esta gran encícl ica el Papa señala las directivas para la participación de los cristianos en la vida pública de los Estados. Exige que sin embargo se construya una civilización impregnada deespíritu cristiano, para lo cual se requiere cierta competencia, ideas claras sobre la verdad, la justicia, el amor y la libertad para poder armonizar la fe con las exigencias dela acción temporal.

El Papa no habla propiamente de un Estado laico pero sí le atribuye al Estado un quehacer con cultura profana no pagana, en donde haya una relación libre y respetuosa entre católicos y no católicos compartiendo la ley Natural y la fidelidad a la moral natural.

El n. 158 precisa el trato entre personas del mismo Estado, distinguiendo que aún aquellas personas que estuvieran en error desde el punto de vista cristiano, siguen siendo personas y el trato humano entre ellos y nosotros debeser de mutuo respeto.

EI n. 160 se refiere a la secularización del Estado, y aunque no dice expresamentequeel Estado debe ser laico, sí entiende que su quehacer debe estar separado de lo religioso aunque no desligado del Derecho Natural para que pueda inspirarse en la Doctrina social de la Iglesia haciéndola suya si fuera necesario y porque dice el Pontífice que la paz social es el verdadero camino para al canzar la Paz universal que es tarea de todos los hombres de buena voluntad (163-172). 
Luis Cordero Rodríguez - Reflexiones socio-jurídicas sobre la separación Iglesia-Estado

\section{EN CONCLUSIÓN}

Inspirado en el pensamiento roncalliano sobreel Estado y su relación con la I glesia, creo yo que el Estado podría llamarse o proclamarse laico a secas, o aconfesional, o separado de la Iglesia, o de "religión laica", o no importa qué, con tal deque, de acuerdo a la realidad más moderna presentada por el Papa, el Estado secular respete la sociedad pluralista desu pueblo en donde todos se traten alturadamente, y se eduquen con la convicción de que existe un Dios trascendente, de quenuestra vida tieneuna responsabilidad eterna, deque lo poco 0 mucho que hagamos será recompensado, de que podemos ser castigados por lo que dejamos de hacer o hacemos mal, deque debemos respetarnos y tolerarnos, y de que el Estado mismo debetratar a todos por igual sin favorecer lo religioso o irreligioso, estando él mismo sujeto a la Ley $N$ atural quees la expresión más clara dela pedagogía y política divina y que al mismo tiempo es la base de la U nidad de todos los ciudadanos deun mismo Estado.

1 Ferrari A.: "Laicitá e religione civile" en Cuadernos de derecho publicados por Morcelliana Brescia (2003)1p. 139.

Davis D. H.: "Civil Religion as a Iudicial Doctrine" en Journal of Church and State N. Y. (1998) I, p.14 Bellah R. : "La religione civile in America" en "Al di lá delle fedi" Morcelliana. Brescia 1975 p. 189.

2 Cuando el Derecho usa los términos "numerus clausus" o "determinación cerrada" está indicando que no se puedeya introducir en la letra y en el espíritu de la norma ningún agregado extensivo o restrictivo de la misma. La Doctrina romanística del Derecho señala por ejemplo que todos los derechos reales son únicos y no se puede introducir ya nuevas figuras por ser númerus clausus (Derechos sobre cosa propia, y Derechos sobre cosa ajena). Cuando por influencia sajona apareció la "propiedad fiduciaria" hubo que recurrirse para entenderla, a la doctrina romana de la "fiducia" y del "fideicomiso" del Derecho sucesorio romano que usó esta figura de propiedad en el caso de la manumisión de un esclavo post mortem, desu antiguo amo.

3 Los peruanos que viven en N. York, o en M iami, o en Chicago, han podido por eso organizar procesiones a la limeña del Señor de los Milagros por ejemplo, entendiendo ellos que por estar en USA tienen el Derecho privado de manifestar su devoción como les venga en gana (como sí la religión fuera un Derecho inherente a la privacidad de cada uno).

4 Sólo pensemos en el Reino U nido en dondela Reina es la defensora de la fe y la Suprema autoridad dela I glesia anglicana y en donde el derecho canónico está a la par que el Common Law.

5 El mismo Papa actual Benedicto XVI ha promovido con mucho vigor una batalla para queen la Constitución de la Europa Unida se reconozca que sus raíces son cristianas, lo que no quedaría claro con la sola alusión a Dioso a la religión. No es una simplecoincidencia queel Papa haya escogido el nombre de Benedicto que hace al usión a S. Benito fundador de Europa y a Benedicto XV, defensor de la unidad cristiana de los pueblos europeos.

6 Hace sólo unos meses la Suprema Corte de los USA se pronunció en contra deun Estado de la Unión que pretendía proscribir la oración al inicio de las clases en una High School, mientras que en Francia con el mismo raciocinio se prohibía a una niña musulmana el uso del velo en la escuela. 